\title{
A COMPARATIVE STUDY OF THE PHYSICAL AND MECHANICAL PROPERTIES OF COARSE AGGREGATES PRODUCED IN OGUN STATE
}

\author{
S. S. Omopariola ${ }^{1, *}$ and A. A. Jimoh ${ }^{2}$ \\ ${ }^{1}$ Civil Engineering DEPARTMEnt, The FEderal Polytechnic Ilaro, Ilaro, Ogun STATE. NIGERIA \\ ${ }^{2}$ Civil EngineEring DePartment, University of ILORIN, ILORIN, KWARA STATE. NIGERIA \\ E-mail addresses: ${ }^{1}$ hfeforchrist@yahoo.com, ${ }^{2}$ aajimoh@yahoo.com
}

\begin{abstract}
This study investigates the compliance of the physical and mechanical properties of granites produced in some parts of Ogun State to relevant codes and standards. The desire to carry out the study was borne by personal on - site experience that single size aggregates produced in some parts of Ogun State do not conform to grading requirements specified in relevant codes and standards. Samples of $9.5 \mathrm{~mm}, 12.5 \mathrm{~mm}, 19 \mathrm{~mm}$ and $25 \mathrm{~mm}$ aggregates were collected from four different quarry sites spread across the state. The Samples were tested for their Specific Gravities, Water Absorptions, Moisture Contents, Aggregates Impact Value and Aggregates Crushing Value in accordance to the relevant standards. Test results reveals that all the samples conform to relevant codes and standards. It was therefore concluded that although the aggregates do not conform to grading specification but the physical and mechanical properties of all the aggregates meet the specifications in relevant codes and standards.
\end{abstract}

\section{Keywords: Evaluation, Physical, Mechanical, Properties, Aggregates and Standards}

\section{INTRODUCTION}

According to [1] aggregates are important constituents containing about 70-80 percent of the volume of concrete. It gives body and strength to the concrete, affects economy and undoubtedly has considerable impact on the properties of concrete. It is therefore very essential to know more about the aggregates which constitutes major volume in concrete so as to know more about concrete and its properties. While in their own opinion, [2] stated that aggregates take about three-quarter of the volume of concrete with the coarse aggregates taking between 50 and $60 \%$ of the concrete mix depending on the mix proportion used. This assertion was supported by [3] when it was stated by them that concrete's fresh and hardened state properties, mix proportions, and economy is strongly influenced by the properties of aggregates.

In [4] it was stated that the types, quality and general properties of aggregates determine the quality of concrete because concrete is made up of about seventy five percent of aggregates. While [1] opined that the properties of aggregates like toughness, hardness, shape, size, soundness, density, and specific gravity affect the strength of concrete. Credence was lent to this by [6] when it was stated that the role of coarse aggregates in the development of strength in concrete is revealed in the high variation in strength between concrete and mortar of the same cement/aggregate proportion. In their own statement, [7] stated that the quality of the concrete is to a great extent determined by the quality of the coarse aggregates and therefore the compressive aggregate strength is an important factor in the selection of aggregate when considering the proportioning of constituent materials of concrete.

Aside from these, [8] as well as [9], opined that aggregate moisture content plays a part in concrete workability because if aggregates are too dry, they will absorb (steal) water from the mix. If aggregates are too wet, the excess moisture must be subtracted from the intended mix water quantity. Some properties of of aggregates were highlighted to include bond, strength, toughness and hardness [10]. According to [10], the compressive strength of concrete cannot significantly exceed the strength of the major part of the aggregate contained therein which can be determined from the crushing strength of aggregate itself prescribed by [11]. According to [12], maximum economy was achieved when aggregates are used and its use considerably improves the volume, stability and durability of the resulting concrete

* Corresponding author, tel: + 234 - 365 - 1888 


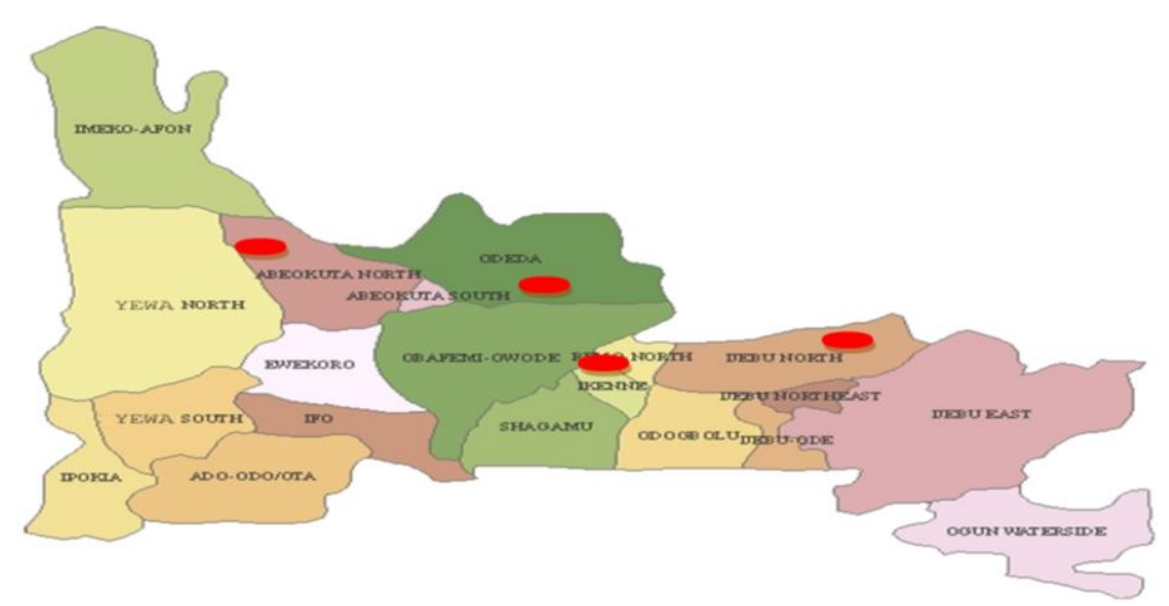

Figure.1: Map of Ogun State Indicating Location of collection of samples

In the opinion of [10] the resistance of aggregate to failure by impact is referred to as the toughness and the value is obtained by determining the impact value (AIV) of bulk aggregate. The test is as described in [11].

\section{METHODOLOGY}

Figure 1 is the map of the study area which is Ogun State in Nigeria. It is located between longitude $3^{\circ} 35^{\prime} \mathrm{E}$ and latitude $7^{0} 00^{\prime} \mathrm{N}$ with landmass of $16,980.55 \mathrm{~km}^{2}$ and a population of about 3,751,140.

Granite samples were procured from four different quarry sites spread across three of the four geopolitical zones of the state. The quarry sites are at Omoologede along Abeokuta - Igboora road and Papa Adeosun along Abeokuta - Ibadan road in Abeokuta North Local Government Area and Odeda Local Government Area respectively, both in Egba geopolitical zone of the state. The two others are at Ishara in Remo North Local Government Area and Ago - Iwoye in Ijebu North Local Government Area in Remo and Ijebu geopolitical zones respectively. The absence of quarry sites in Yewa/Awori geopolitical zone of the state was responsible for its exclusion.

The physical properties considered for laboratory tests are specific gravity, water absorption and moisture content which was carried out in accordance with [1] and [13]. The specific gravity (SG) and absorption (ABS) were then calculated using the equations (1) and (2) respectively, while the moisture content was evaluated using equation (3).

$$
\begin{aligned}
S G & =\frac{A}{B-C} \\
A B S & =\frac{\mathrm{B}-\mathrm{A}}{\mathrm{A}} \times 100 \%
\end{aligned}
$$

Where A is weight of oven-dry sample in air (g), B is weight of SSD sample in air (g) and C is the weight of SSD sample in water.
Moisture Content MC in (\% dry mass) is goiven by:

$$
M C=\frac{(M 2-M 3)}{(M 2-M 1)} \times 100 \%
$$

The result is reported to the nearest $0.1 \%$ of the dry weight. While the mechanical properties tested are Aggregate Impact Value (AIV) evaluated in accordance with the specifications in [14] and Aggregate Crushing Value (ACV) evaluated in accordance with the specifications in [15]. The percentage fines is given by:

$$
\text { Percentage fines }=\frac{B \times 100}{A}
$$

In (4) A is the mass of surface-dry sample (g) and B is the mass of the fraction passing the $2.36 \mathrm{~mm}$ sieve (g).

\section{RESULTS AND DISCUSSION}

The results and findings from the study are presented below.

\subsection{Specific Gravity}

Figure 1 is the value of the specific gravity of all the different sizes of aggregates for all quarry sites. The values contained therein indicates that the specific gravity of all the different sizes of aggregates for all quarry sites are within the limits of $2.4-3.0$ stated in literature $[1,4,16,17]$. The values are also above the minimum value specified in [11]. By comparison, aggregates from both Omoologede and Ishara has the specific gravity of 2.78 which is the highest while that from Papa Adeosun has the least value of 2.63 for $9.5 \mathrm{~mm}$ aggregates. In the case of $12.5 \mathrm{~mm}$, the highest value of 2.71 was recorded for aggregates from both Omoologede and Papa Adeosun with that of Ago Iwoye recording the least value of 2.66 . The highest value of 2.86 was obtained for aggregates from Ago Iwoye and the least value of 2.61 was obtained for Ishara for $19 \mathrm{~mm}$ aggregates. For $25 \mathrm{~mm}$ aggregates, aggregates from Omoologede has the specific gravity of 2.74 which 
is the highest while that from Papa Adeosun has the least value of 2.68 .

\subsection{Moisture Content}

As can be seen in Figure 2, the moisture content for the different sizes of aggregates varies from one quarry site to another. While for $9.5 \mathrm{~mm}$ aggregates, the aggregate from Omoologede quarry site has the highest and that from Ago - Iwoye has the lowest. In the case of $12.5 \mathrm{~mm}$ and $19 \mathrm{~mm}$ aggregates, aggregates from Ago Iwoye quarry site has the highest and that from Ishara has the lowest. For 25mm aggregates, aggregate from Papa Adeosun quarry site has the highest and that from Ago - Iwoye has the lowest. It can also be observed that the moisture content decreases as the aggregate size reduces for all the quarry sites except for that of Ago Iwoye where that of $12.5 \mathrm{~mm}$ is higher than that of $9.5 \mathrm{~mm}$. However, the values of moisture content for all the coarse aggregate falls within the limits stipulated in previous literatures. In [18] it was stated that the moisture content can range from less than one percent in gravel to up to 40 percent in very porous sandstone and expanded shale. The moisture content of all the aggregates obtained from the various quarry sites fall below the recommended value of $3 \%$ as specified in [17].

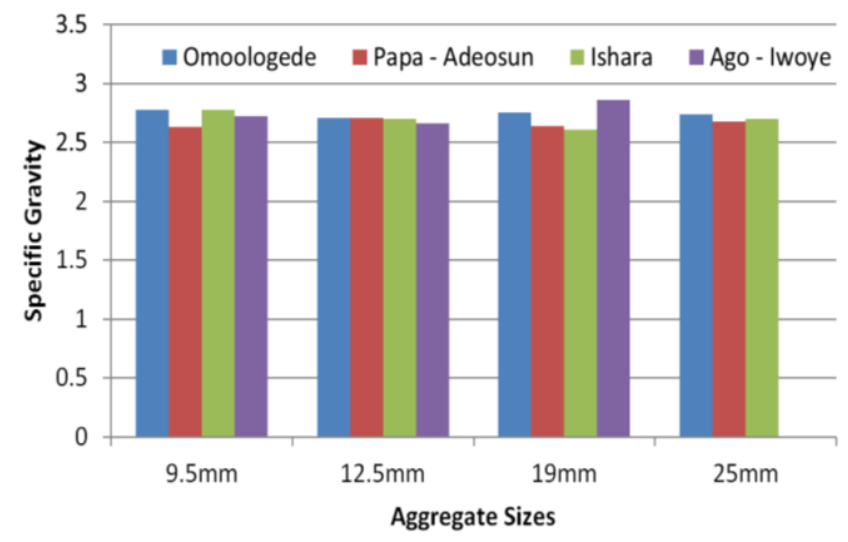

Figure 2: Values of Specific Gravity of different Aggregate Sizes from Various Quarry Sites

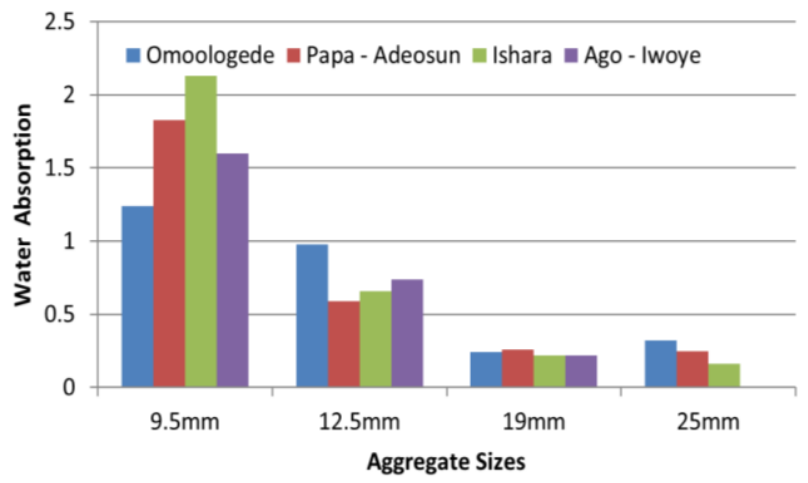

Figure 4: Values of Water Absorption of Different Aggregate Sizes from Various Quarry Sites

\subsection{Water Absorption}

The values indicated in figure 3 indicates that the water absorption of all the different sizes of aggregates for all quarry sites are within the limits of $1 \%-3 \%$ stated in literature and British Standards [11, 18 - 21]. It therefore follows that all the aggregates tested have very low water absorption values and hence are very suitable for concreting works. Comparatively, the aggregate from Ishara quarry site has the highest water absorption value and that from Omoologede has the lowest value for $9.5 \mathrm{~mm}$ aggregate sizes. In the case of $12.5 \mathrm{~mm}$ aggregates, that from Ago - Iwoye quarry site has the highest and that from Ishara has the lowest. For $25 \mathrm{~mm}$ aggregates, aggregate from Papa Adeosun quarry site has the highest and that from Ago - Iwoye has the lowest.

\subsection{Aggregate Impact Value and Aggregate Crushing Value}

Values from figure 4 indicates that the Aggregates Impact Value of all the different sizes of aggregates for all quarry sites are lesser than $30 \%$ value stated in literature and British Standards $[6,11]$ and specified in [10].

It therefore follows that Aggregates Impact Value of all the aggregates tested are very suitable for concreting works.

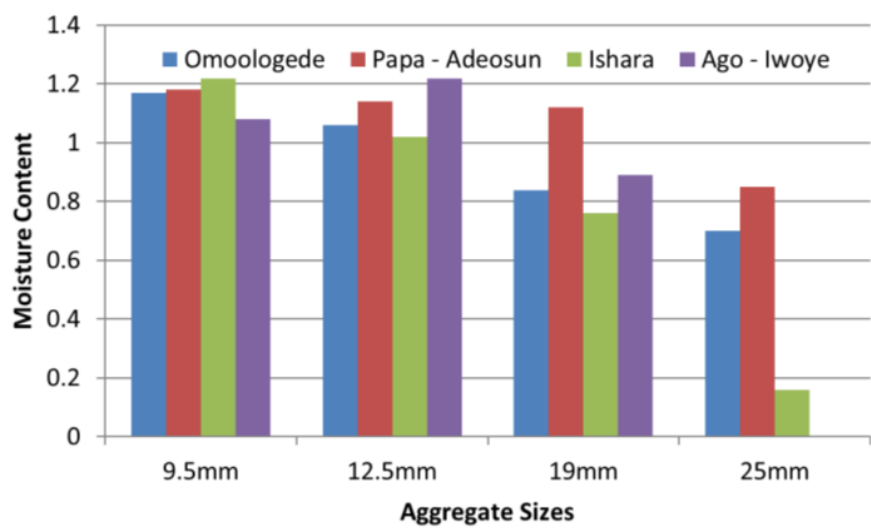

Figure 3. Values of Moisture Content of different Aggregate Sizes from Various Quarry Sites

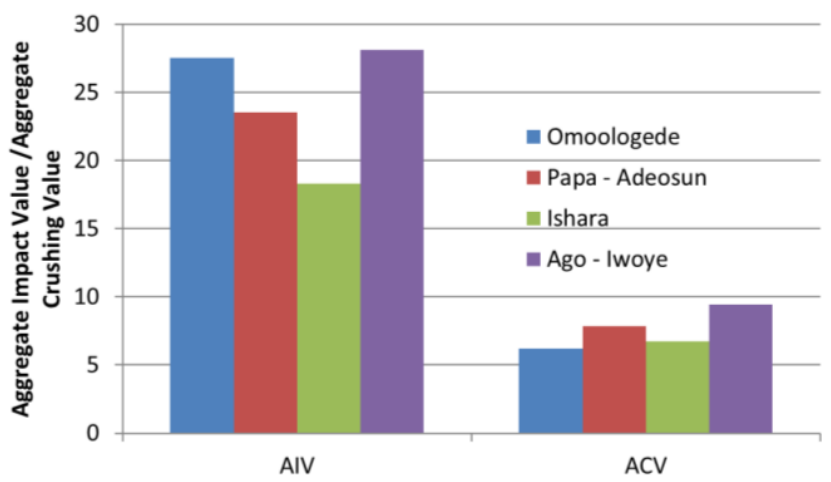

Figure 5: Aggregate Impact and Aggregate Crushing ValueS of different Aggregate Sizes from Various Quarry Sites 
As for the Aggregate Crushing Value, all the different sizes of aggregates for all quarry sites has values that are lesser than $35 \%$ value allowed for concreting works as stated in literature [11]. The average value of the Aggregate Crushing Value for the coarse aggregates samples considered in this research is between $6.2 \%$ and $9.45 \%$. This is considerably lower than stated values in literature therefore, it can be said that the aggregates has a considerable lower value and is therefore very suitable for concreting work. By way of comparison, aggregate from Ago Iwoye has the highest values of $28.12 \%$ and $9.45 \%$ for impact and crushing values respectively. While aggregate from Ishara has the least value of $18.12 \%$ for impact value and that from Omoologede has the least crushing value of $6.21 \%$.

\section{CONCLUSION}

It can be concluded from the results obtained that there are variations in both the physical and mechanical properties of aggregates varies considerably from location to location. It was also concluded that there are variations between the various sizes of aggregates at each quarry site also varies

\section{RECOMMENDATIONS}

It is therefore recommended that since the physical and mechanical properties are in conformity with relevant codes and standards, they are suitable for use in concrete work. However for optimum characteristic strength, the various sizes should be combined in appropriate proportions to conform to grading requirements in relevant codes and standards.

\section{REFERENCES}

[1] Shetty M. S. Concrete Technology Theory and Practice S. Chand \& Company Ltd. Ram Nagar, New Delhi .

[2] Ajamu S.O., Ige J.A. And Oloyede, "Effect of Coarse Aggregate Size on the Compressive Strength and Flexural Strength of Concrete Beam", International Journal of Engineering Research and Application 5,(4) 67-75, 2005.

[3] Kumar P. R. and Rao K. M.V., A Study on the Effect of Size of Aggregate on the Strength and Sorptivity Characteristics of Cinder Based Light Weight Concrete, Research Journal of Engineering Sciences Vol.1(6), 27-35, 2012.

[4] Neville A. M. Properties of Concrete, 5th edition. Pearson Education Limited 2011

[5] Apebo, N. S, Ioruwa, M. B. and Agunwamba, J. C. "Comparative Analysis of the Compressive Strength of Concrete with Gravel and Crushed Over Burnt Bricks as Coarse Aggregates" Nigerian Journal of Technology, Vol. 32, No. 1, pp. 7 - 12, 2013.

[6] Zerdi A.T., Strength Exhibition of M25 Grade Concrete With Limestone Quarry Dust Utilization for Fine Aggregates, Global Journal of Research Analysis International Vol. 5, Issue 1, 2016 No.3, 2014.

[7] Aginam C. H. Chidolue, C. A. and Nwakire, C. Investigating the Effects of Coarse Aggregate Types on the Compressive Strength of Concrete, International Journal of Engineering Research and Application 5,(4) 67-75 Vol. 3, Issue 4, pp. 1140-1144Jul-Aug 2013.

[8] Chen, B and Liu J, "Effect of Aggregate on the Fracture Behaviour of High Strength Concrete" Construction and Building Materials. 18(8), pp 585 - 590, 2004.

[9] Rao, G.A. and Prasad, B.K.R., "Fracture Energy and Softening Behaviour of High Strength Concrete" Cement and Concrete, 32(2), 2002.

[10] Neville A. M. and Brooks J.J. Concrete Technology, 2nd edition. Prentice Hall, 2010

[11] British Standard Institutes, BS EN 1097-6:2000, Tests for mechanical and physical properties of aggregates. Determination of particle density and water absorption, British Standard Institution, London.

[12] Adaba, C. S., Agunwamba, J. C., Nwoji, C. U., Onya, O. E., Oze, S, "Comparative Cost And Strength Analysis of Cement And Aggregate Replacement Materials", Nigerian Journal of Technology, Vol. 31, No. 2, pp. 111 - 115, 2012.

[13] British Standard Institute, BS 812: Part 109. "Methods for Determination of Aggregates Moisture", British Standard Institution London, 1990.

[14] British Standard Institute, BS 812: Part 112, "Methods for Determination of Aggregates Impact Value", British Standard Institution London, 1990.

[15] British Standard Institute, BS 812: Part 110, "Methods for Determination of Aggregates Crushing Value", British Standard Institution London, 1990.

[16] Arumugam, B. Effect of Specific Gravity on Aggregate Varies the Weight of Concrete Cube, International Journal of Civil Engineering, volume 1 Issue 3, 2014, pp 1-9.

[17] Nemati, K.M., Concrete Technology, Aggregates for Concrete 2015, pp 1-16,

[18] British Standard Institutes, BS 882:1992, Specification for aggregates from natural sources for concrete

[19] British Standard Institutes, BS 12620: 2002, Aggregates for concrete, British Standard Institution, London.

[20] British Standard Institutes, BS 1047:1983, Specification for air-cooled blast furnace slag Aggregate for use in construction.

[21] British Standard Institutes, BS 8007:1987, Code of practice for the design of concrete structures for retaining aqueous liquids

[22] British Standard Institutes, BS 8007:1987, Code of practice for the design of concrete structures for retaining aqueous liquids. 